\title{
ALUNOS INDÍGENAS NA UNIVERSIDADE: o que mudou nas práticas curriculares do professor do ensino superior?
}

\author{
Maria Antonia Vidal Ferreira ${ }^{1}$ \\ Lucas de Vasconcelos Soares² \\ Taciara Soares Castro ${ }^{3}$
}

\begin{abstract}
RESUMO
O estudo visa analisar as percepções docentes sobre a inserção de estudantes indígenas no ensino superior e principais mudanças nas suas práticas curriculares, averiguando a existência de políticas de ações afirmativas e sua implementação nas ações cotidianas do processo ensino-aprendizagem. Para tanto, utiliza-se, como lócus de reflexão, o contexto da Universidade Federal do Oeste do Pará (Ufopa). As discussões são fruto de uma pesquisa, contemplando, além do levantamento bibliográfico, a análise documental e aplicação de questionários semiestruturados a 35 docentes atuantes no ensino superior, somando-se as experiências acumuladas em outras etapas do projeto. Dos resultados obtidos, destacam-se importantes desafios postos ao trabalho docente, como: necessidade de compreender as normas da língua portuguesa pelos indígenas; capacidade de intervir (dos professores) em situações de discriminação visíveis em sala de aula; falta de interesse dos alunos; desprezo pelas regras e acordos acadêmicos, como a não realização de avaliações e atividades nos prazos estabelecidos. Em síntese, verificou-se que a Ufopa instituiu sua política de ações afirmativas e de promoção da igualdade étnico-racial, embora nem todos os docentes a conheçam plenamente, enfraquecendo a materialidade dos processos. Assim, visando superar os dilemas nas práticas curriculares, os docentes apontam: a criação de materiais específicos na língua indígena; oferta obrigatória de cursos de língua portuguesa ao longo da formação; e a inserção de questões indígenas (saberes, territórios, etc.) no currículo, como possibilidades de diálogo intercultural e interepistêmico.
\end{abstract}

Palavras-chave: Educação Superior Indígena. Práticas Curriculares. Universidade Pública.

\footnotetext{
${ }^{1}$ Doutora em Educação pela Universidade Estadual de Campinas (Unicamp). Docente do Magistério Superior na Universidade Federal do Oeste do Pará (Ufopa). Integrante do Grupo de Estudos e Pesquisas "História, Sociedade e Educação no Brasil - HISTEDBR/UFOPA". Orcid iD: http://orcid.org/0000-0002-9127-8555. E-mail: ferreira-mv@uol.com.br

${ }^{2}$ Mestrando em Educação pelo Programa de Pós-graduação em Educação (PPGE) da Universidade Federal do Oeste do Pará (Ufopa). Especialista em Gestão Escolar. Graduado em Licenciatura em Pedagogia. Integrante do Grupo de Estudos e Pesquisas "História, Sociedade e Educação no Brasil - HISTEDBR/Ufopa". Bolsista da Coordenação de Aperfeiçoamento de Pessoal de Nível Superior (Capes). Orcid iD: http://orcid.org/0000-00025784-8307. E-mail: lu.cas.soares@bol.com.br

${ }^{3}$ Estudante do curso de Licenciatura em Pedagogia na Universidade Federal do Oeste do Pará (Ufopa), Campus Óbidos. Orcid iD: http://orcid.org/0000-0001-9657-7637. E-mail: eventoscomclasse@gmail.com
} 


\title{
INDIGENOUS STUDENTS AT THE UNIVERSITY: what has changed in the curricular
}

\author{
practices of the higher education teacher?
}

\begin{abstract}
The study aims to analyze the teachers' perceptions about the insertion of indigenous students in higher education and the main changes in their curricular practices, investigating the existence of affirmative action policies and their implementation in the daily actions of the teaching-learning process. For that, the context of the Federal University of Western Pará (Ufopa) is used as a locus for reflection. The discussions are the result of research, contemplating, in addition to the bibliographical survey, documentary analysis and application of semi-structured questionnaires to 35 professors working in higher education, adding to the experiences accumulated in other stages of the project. From the results obtained, important challenges for teaching work stand out, such as: the need to understand the norms of the Portuguese language by the indigenous people; ability to intervene (of teachers) in situations of discrimination visible in the classroom; lack of interest from students; disregard for academic rules and agreements, such as failure to carry out evaluations and activities within the established deadlines. In summary, it was found that Ufopa instituted its policy of affirmative actions and the promotion of ethnic-racial equality, although not all teachers are fully aware of it, weakening the materiality of the processes. Thus, in order to overcome the dilemmas in curricular practices, the teachers point out: the creation of specific materials in the indigenous language; mandatory offer of Portuguese language courses throughout the training; and the inclusion of indigenous issues (knowledge, territories, etc.) in the curriculum, as possibilities for intercultural and inter-epistemic dialogue.
\end{abstract}

Keywords: Indigenous Higher Education. Curricular Practices. Public university.

\section{ESTUDIANTES INDÍGENAS EN LA UNIVERSIDAD: qué ha cambiado en las prácticas curriculares del profesor de educación superior?}

\section{RESUMEN}

El estudio tiene como objetivo analizar las percepciones de los docentes sobre la inserción de los estudiantes indígenas en la educación superior y los principales cambios en sus prácticas curriculares, investigando la existencia de políticas de acción afirmativa y su implementación en las acciones cotidianas del proceso de enseñanza-aprendizaje. Para ello, se utiliza el contexto de la Universidad Federal de Western Pará (Ufopa) como lugar de reflexión. Las discusiones son fruto de la investigación, que incluye, además del relevamiento bibliográfico, el análisis documental y la aplicación de cuestionarios semiestructurados a 35 profesores que laboran en la educación superior, sumándose a las experiencias acumuladas en otras etapas del proyecto. De los resultados obtenidos se destacan importantes desafíos para la labor docente, tales como: la necesidad de comprender las normas de la lengua portuguesa por parte de los indígenas; capacidad de intervenir (de los profesores) en situaciones de discriminación visibles en el aula; falta de interés de los estudiantes; Incumplimiento de normas y acuerdos académicos, como no realizar evaluaciones y actividades dentro de los plazos establecidos. En resumen, se constató que la Ufopa instituyó su política de acciones afirmativas y la 
promoción de la igualdad étnico-racial, aunque no todos los docentes son plenamente conscientes de ello, debilitando la materialidad de los procesos. Así, para superar los dilemas en las prácticas curriculares, los docentes señalan: la creación de materiales específicos en lengua indígena; oferta obligatoria de cursos de portugués a lo largo de la formación; y la inclusión de los temas indígenas (saberes, territorios, etc.) en el currículo, como posibilidades de diálogo intercultural e interepistémico.

Palabras clave: Educación superior indígena. Prácticas curriculares. Universidad pública.

\section{INTRODUÇÃO}

A discussão em torno da presença indígena no campo educacional não é algo recente. Pelo contrário, inúmeras lutas foram travadas no decorrer dos anos para ampliar a oferta de educação escolar a este público, ainda marginalizado pela sociedade por sua condição histórica de inferioridade fixada no país. Ampliar este debate ao ensino superior constitui um amplo desafio, considerando as características originárias em torno da formação das universidades públicas, direcionadas, inicialmente, as elites dominantes (SOARES; COLARES; FERREIRA, 2020).

Sob essa perspectiva, o estudo visa analisar as percepções docentes sobre a presença indígena no ensino superior e quais têm sido as principais mudanças nas práticas curriculares desse professor, averiguando a existência de políticas de ações afirmativas e sua implementação nas ações cotidianas do processo ensino-aprendizagem. Para tanto, utiliza-se, como lócus de reflexão, o contexto da Universidade Federal do Oeste do Pará (Ufopa), instituição pública situada na região amazônica do Brasil.

Dos objetivos propostos, buscou-se: a) compreender os percursos históricos, políticos e sociais viabilizadores da inserção indígena no ensino superior no Brasil; b) sistematizar a presença indígena nos cursos de nível superior da Ufopa e suas políticas de ações afirmativas; e c) refletir, a partir da percepção de docentes do ensino superior da Ufopa, as principais mudanças, alinhamentos, desafios e perspectivas em torno do trabalho com estudantes indígenas na universidade.

As discussões são fruto de uma pesquisa de campo, contemplando, entre as técnicas de coleta de dados, o uso de levantamento bibliográfico, 
a partir do acesso as contribuições teóricas e estudos desenvolvidos sobre o tema; análise documental, em relatórios da Ufopa e demais políticas públicas relacionadas ao público e modalidade contemplada; e aplicação de questionários semiestruturados a trinta e cinco (35) docentes, de diferentes cursos, atuantes no ensino superior na Ufopa, contemplando questões centrais referentes às práticas, mudanças, desafios e perspectivas. Soma-se a estes, as experiências e constatações obtidas ao longo do desenvolvimento do projeto de pesquisa que originou o estudo.

O embasamento teórico selecionado centrou-se, inicialmente, nas discussões de Baniwa (2013), Collet e Paladino (2014), Mejía Jiménez (2016), Soares, Colares e Ferreira (2020) e Viana (2014), seguido por outros estudiosos do tema. Utiliza-se ainda a análise de importantes documentos, entre eles: as Leis № 9.394/1996 e No 12.711/2012 e o Plano de Formação Básica Indígena da Ufopa.

O artigo está organizado em três seções: na primeira, discutem-se os percursos histórico-político-sociais favoráveis à inserção indígena no ensino superior brasileiro (Povos indígenas na universidade: diálogo intercultural e construção de relações interétnicas nas salas de aula); a segunda tem como foco sistematizar a presença indígena nos cursos de ensino superior da Ufopa e suas políticas internas viabilizadoras (Indígenas na Ufopa: acesso, garantias e organização); e na terceira, contemplando a percepção dos docentes, tratam-se dos principais desafios, mudanças, alinhamentos e perspectivas nas práticas curriculares do ensino superior no âmbito da Ufopa (O indígena no ensino superior: e agora professor?). A seguir, discute-se cada uma.

\section{POVOS INDÍGENAS NA UNIVERSIDADE: diálogo intercultural e construção de relações interétnicas nas salas de aula}

Lugar de preto é na senzala, lugar de mulher é na cozinha, lugar de índio é na aldeia, lugar de branco abastado é na escola se formando para dominar a todos e todas. Esse é o discurso ideológico, oculto, lacunar. Discurso silencioso, percebido nas entrelinhas, mas também nos gestos, falas do senso comum, posturas e atitudes que atravessam a sociedade de um 
modo geral e, em especial, o sistema educacional do nosso país, portanto, um discurso legal proveniente da elite dominante.

Como pensar diferente, se fomos colonizados pelo branco europeu? Se estruturalmente nossa sociedade se ergueu sob esse paradigma? Assim, era natural ao branco dominar as outras etnias; ao homem dominar a mulher; ao rico dominar o pobre. Sob essa forma de pensar, até a violência se justificava para impor esse domínio a quem, porventura, se rebelasse.

Foi assim, sob o prisma da bipolaridade esquizofrênica que nossa sociedade se estruturou por séculos e, sendo a escola, uma instituição que integra essa sociedade, a mesma absorve 0 pensamento estrutural societário. Falamos de escola porque nem se vislumbrava por muitos e muitos anos a ideia de índio, negro e pobre acessar o ensino superior. Para isso era necessário descolonizar a universidade.

O ensino superior, no Brasil, tem suas origens em 1550. Foi um estabelecimento fundado pelos jesuítas, na Bahia, que era, então, a sede do governo geral. Os jesuítas criaram 17 colégios para os filhos de funcionários públicos, de senhores de engenhos, de criadores de gados, de artesãos. Em 1553 começaram a funcionar os cursos de Artes e de Teologia e no século XVIII surgiram os cursos de Matemática. Nesse mesmo século, o ensino superior se expandiu também para $O$ Rio de Janeiro, São Paulo, Pernambuco, Maranhão e Pará (LOPES; FARIA FILHO; VEIGA, 2015).

Entretanto, no século XIX, com a instalação da família real e da transferência do poder metropolitano para o Brasil, o que coincidiu com a formação do Estado Nacional, o ensino superior foi reconfigurado, diferente do que foi erigido na colônia.

O modelo napoleônico, sendo originário do Estado Nacional, se caracteriza pelo monopólio estatal, é laico e de estrutura compartimentalizada, com foco na formação profissional. Esta estrutura compartimentalizada se evidencia pela divisão em faculdades, centros e departamentos. Fica evidente, neste modelo, o atendimento aos interesses do Estado, na formação dos seus governantes e nos interesses da elite em detrimento dos interesses das classes populares e da sociedade em geral. 
Por outro lado, a universidade popular, da forma como a sonhamos, não é algo impossível, pelo contrário, sua construção poderá se erigir a partir de um alicerce já fundado desde o início do século XIX. Reporta-se a Raul Mejia (2016, p. 38), quando este se refere à educação popular na América Latina como um processo, cujos registros "tem acompanhado a dinâmica da sua construção". Os marcos principais desse alicerce vem das "repúblicas emergentes, universidades populares, escolas de educação, pedagogias da libertação, o que permite mostrar a vitalidade que é invisivel, mas está presente neles". Essa base foi "fundada no diálogo, no confronto de saberes e na negociação cultural, tornando possível a prática de um exercício educativo que integra intraculturalidade, interculturalidade e transculturalidade $[. .$.$] , reconhecendo que somos humanamente diferentes,$ culturalmente diversos".

Segue o autor falando sobre a história da educação popular como proposta de rompimento da visão europeia, que embora pareça um pensamento original, na verdade foi o resultado de um processo de disputa e de muitas lutas históricas, embrionadas nas nascentes repúblicas. Tais lutas deram sentido, a uma proposta, na qual vai tomando sentido a "especificidad en lo pedagógico y en lo metodológico", de acordo com algumas concepções emblemáticas de autores, como: (1) Simón Rodríguez (1975), para quem a América não deve imitar a Europa, mas ser original. Questiona o padrão eurocêntrico, de homogeneização e subordinação intelectual; (2) Paulo Freire, para quem a educação deve ser entendida como práxis libertadora tanto para o oprimido quanto para o opressor. Sua proposta pedagógico-metodológica é política porque empodera quem dela participa para se tornarem autores de sua história. A pedagogia freiriana, alicerça-se no diálogo crítico e libertador. Na proposta de libertação, a educação popular veio se constituindo com a força da negociação cultural viabilizada pelo diálogo e confrontação de saberes.

Contrariando o raciocínio em que o diálogo entre saberes é realizado sob condições de subalternidade, na qual a cultura local se desenvolve a partir da lógica do conhecimento ocidental, Raul Mejia defende que o 
diálogo opere em dinâmicas e processos que dê lugar à multiculturalidade, a confrontação de saberes, ou seja, dinâmicas de complementariedades de um mundo de pluralismo epistêmico.

A confrontação de saberes é o momento em que se dá visibilidade à negação do outro, por exemplo, dos saberes populares em nome da ciência, o comunitário em nome do individual, do multicultural em nome do monocultural, o sentido em nome da razão e muitos outros dualismos instituídos para negar ou inviabilizar o outro. Assim, essa confrontação de saberes e conhecimentos permite a superação das exclusões epistemológicas, uma vez que viabiliza a negociação cultural. Segundo o autor, é um exercício metodológico que empodera os grupos e pessoas de comunidades de aprendizes, originando uma massa crítica.

Os estudos de Raúl Mejía indicam um processo metodológico para a educação popular em três passos: (1) diálogo não linear de saberes (a interculturalidade), que gera a (2) confrontação de saberes, que por sua vez, gesta (3) negociação cultural, que gesta os processos de transformação baseados em acordos, forjando a transculturalidade. Trata-se de um volume teórico-prático consolidado com fundamentos conceituais, políticos, pedagógicos, metodológicos, epistemológicos para dar vida à proposta educativa de natureza popular desde a escola à universidade.

A colonização portuguesa nos legou, pelo menos, duas características marcantes que atravessaram um lastro histórico de 1550 até a década de 19904 absorvidas pela sociedade e que reverberaram no modelo de universidade como a concebemos hoje. As duas características se referem ao currículo monocultural, seguindo, inicialmente, o modelo napoleônico. Ou seja, O Brasil Colônia, nas palavras de Cunha (2015, p. 154), "criou cátedras isoladas de ensino superior para a formação de profissionais, [...]: de Medicina, na Bahia e no Rio de janeiro, em 1808, e de Engenharia, embutidas na Academia Militar, no Rio de Janeiro, dois anos depois". E no

4 Esse marco de 1990 é definido por situar dois diplomas legais importantes para a democratização do país. A Constituição cidadã de 1988 e a Lei de Diretrizes e Bases da Educação Nacional - LDB No 9.394/96. A CF de 1988 alavancou um conjunto de legislações no âmbito educacional como veremos no decorrer desse artigo. 
período do Império, em 1827, "imperador Pedro I acrescentou [...] os cursos Jurídicos em Olinda e em São Paulo, com o que se completava a tríade dos cursos profissionais superiores que por tanto tempo dominaram o panorama do ensino superior no país: Medicina, Engenharia e Direito".

O segundo fato marcante desses mais de cinco séculos, incrustrados na história das nossas universidades, é o seu caráter seletivo e excludente. A leitura de Cunha (op. cit) nos remete a presumir que a mesma evoluiu de um centralismo estatal, com relativa expansão entre a primeira década da república, marcada pela facilitação do acesso ao ensino superior 5 , seguido de uma contenção no período de 1911, com a Reforma Rivadávia Corrêa (então, titular do Ministério da Justiça e dos Negócios Interiores). Tal reforma, entre outras orientações, cortava os privilégios do colégio Pedro II, de isenção de testes para ingresso ao ensino superior, bem como das faculdades federais "de emitir diplomas conferidores de exclusividade profissional" (Op. cit). Na Reforma Carlos Maximiliano (ministro de Interior), em 1915, os exames de admissão são rebatizados de exames vestibulares, além de manter pontos da reforma anterior, esta propõe mudanças profundas, reorganiza o ensino secundário e superior no país.

Uma relativa ampliação de acesso ao ensino superior é identificada na década de 1990 em diante, decorrente de duas situações: o aumento do contingente de estudantes no ensino médio e a consequente pressão desse contingente ao acesso ao ensino superior e a redemocratização do país.

A conquista do espaço universitário pelos indígenas, ou a conquista da formação em nível superior, significa a luta de indivíduos e coletivos indígenas por um lugar digno na sociedade brasileira. Luta essa, que vem de longa data sendo desenhada, sobretudo a partir dos anos 1990, na esteira do novo quadro de reconhecimento de direitos proporcionado pela Constituição Federal de 1988 (VIANA, 2014).

\footnotetext{
5 Diversos fatores, segundo Cunha (2015), contribuíram pra essa expansão: a) aumento da procura pelo ensino superior, produzido pelas transformações econômicas, associada à multiplicação das faculdades, b) a luta dos liberais e positivistas pelo "ensino livre"; c) a adoção de privilégios dos concluintes do Colégio Pedro II e outras escolas secundárias que dispensavam de seus ex-alunos os exames preparatórios para o ingresso.
} 
Os anos subsequentes à Constituição fortaleceram o movimento indigenista por uma educação "diferenciada, intercultural". Reportando-se a CF/1988, Viana (2014, p. 15), "segundo seus usos, costumes e tradições".

Entretanto, e até que se chegasse a esse patamar, tinha-se o legado da colonização do Brasil, que investiu cruelmente na aculturação indígena. "Assim, desde a colonização do Brasil, políticas de Estado vêm sendo executadas no sentido de assimilar os indígenas à sociedade brasileira e anular sua identificação étnica" (COLLET; PALADINO; RUSSO, 2014, p. 18).

Ou seja, no Brasil, ocorreu um grave equívoco, logo de raiz, quando da criação de escolas para indígenas e não indígenas. Se, na raiz da nossa civilização se edificaram tais distorções, que foram consolidadas ao longo da história, muito ainda precisa ser feito para equacionar essa questão.

As vozes reivindicatórias começaram pela proposição de uma educação escolar indígena ao nível básico, com professores nativos e bem formados, o que se traduz como dotados de formação em nível superior. Não somente a formação em nível superior de professores, mas também a formação de enfermeiros, médicos, nutricionistas, agrônomos, engenheiros florestais, ambientais e de pesca, ecólogos, advogados, administradores, cientistas sociais, especialistas em informática e em todos os demais campos que a imaginação indígena conceber como desejáveis (VIANA, 2014, p. 19).

O autor chama a atenção para uma questão fundamental que é a "coexistência nas contemporâneas condições de vida indígena, entre saberes tradicionais e universitários, cuja articulação não é trivial", assim como a capacidade de administrar a aludida tensão entre os chamados conhecimentos 'locais' e 'universais' (VIANA, 2014, p. 20).

Trata-se de criar condições para se estabelecer um diálogo intercultural e de se construir relações interétnicas na sala de aula universitária. Pode-se arriscar dizer que inserção indígena no ensino superior tem sido um vetor para isso. Em 2012 foi sancionada a Lei № 12.711, também conhecida como Lei das Cotas, na qual são beneficiados estudantes carentes, negros e pardos e índios de escolas públicas. 
A Lei das cotas tem como finalidade corrigir uma histórica exclusão social e educacional desses segmentos, compondo o rol de políticas afirmativas da sociedade brasileira. A lei obriga as instituições de ensino superior federais a reservarem vagas para índios, negros e pardos. Essa distorção histórica se explica pelo enorme contingente populacional formado pelos negros e índios, que contribuíram significativamente com a economia e o desenvolvimento do país, mas que não usufruíram desse desenvolvimento (SOARES; COLARES; FERREIRA, 2020).

Ao se analisar o conjunto de políticas públicas, é visível o crescente reconhecimento da importância da educação superior, não apenas por ser determinante para a formação acadêmico-profissional e para as atividades de pesquisa a nível científico e tecnológico, mas igualmente em função da posição estratégica que o Brasil ocupa nas políticas públicas voltadas a cidadania democrática e a justiça social.

Porém, ao se implementar uma política dessa natureza, é necessário considerar as condições concretas de cada universidade, seu currículo e proposta pedagógica. No caso da educação indígena, há que se pensar nas finalidades do conhecimento que esse povo precisa para sua emancipação.

\footnotetext{
Estes povos desejam formação superior em seus termos, ou seja, para atender suas demandas, realidades, projetos e filosofias de vida. Aqui reside o maior desafio da formação superior de indígenas nos contextos das atuais IES, fundamentadas na organização, produção e reprodução de saber único, exclusivo, individualista e a serviço do mercado. O desafio é como esta instituição superior formadora pode possibilitar a circulação e a validação de outros saberes, pautados em outras bases cosmológicas, filosóficas e epistemológicas (BANIWA, 2012, p. 19).
}

Os povos indígenas nos convidam a pensar sobre a existência de outros saberes para além da lógica academicista que, conforme Baniwa (2012, p. 19), sustenta o capitalismo individualista, que tem gerado a exploração econômica desumana e a lei do mais rico e dos que tem poder político. "Os povos indígenas gostariam de compartilhar com o mundo, a partir da universidade, seus saberes, seus valores comunitários, suas 
cosmologias, suas visões de mundo e seus modos de ser, de viver e de estar no mundo, onde o bem viver coletivo é a prioridade".

\section{INDÍGENAS NA UFOPA: acesso, garantias e organização}

A Ufopa, criada pela Lei $N^{0} 12.085 / 2009$, incorporou-se na proposta de ampliação do ensino superior, instalando-se na Amazônia há mais de 10 anos com, aproximadamente, 6.000 alunos distribuídos entre os 49 cursos de graduação e 15 de pós-graduação. Referente à forma de ingresso, a universidade tem como carro-chefe as notas obtidas no Enem (Processo Seletivo Regular), bem como os Processos Seletivos Especiais pelo uso de cotas sociais. Entre estes, o Processo Seletivo Especial Indígena (PSEI), com início em 2012, através da Lei No 12.711 (SOARES; COLARES; FERREIRA, 2020).

A partir da Lei de Cotas, iniciando um fluxo ingressante cada vez mais diversificado ao ensino superior, a Ufopa implementa suas próprias resoluções, programas e ações com a finalidade de democratizar o acesso e garantir a permanência dos estudantes na universidade. Estudos recentes (SOARES; COLARES; FERREIRA, 2020, p. 76) contabilizam que:

\section{[...] a Universidade Federal do Oeste do Pará - UFOPA [...] ofertou, no processo seletivo de 2019, 1.413 vagas aos cursos de graduação, sendo 711 reservadas ao sistema de ingresso por cotas. [...] o Processo Seletivo para Indígenas - PSEl, que neste ano recebeu mais de 600 indígenas inscritos para 81 vagas disponibilizadas. [...] Uma das pretensões de 2020 é ampliar o sistema de cotas para o ingresso de [...] indígenas em todos os programas de pós-graduação [...].}

Ainda sobre o acesso pelo sistema de cotas, O PSEl é compreendido como uma iniciativa de "[...] fortalecimento das ações afirmativas que visam ampliar e a diversificar as oportunidades educacionais [...] de acordo com as necessidades da região" (UFOPA, 2015), contribuindo na oferta do ensino superior aos estudantes indígenas, pois, considera-se que sem estas políticas tais grupos permaneceriam sem o direito à educação, já que o sistema continua excludente e seletivo com os povos historicamente desfavorecidos (RODRIGUES, 2018). Entre os critérios estabelecidos, tanto na definição dos processos de seleção quanto do número de vagas, utilizam-se "[...] seminários descentralizados, ouvindo as lideranças indígenas [...]" (UFOPA, 
2015, p. 68). Sistematicamente, a seleção se dá por meio de provas escritas de conhecimentos específicos (interligados a própria realidade) e entrevistas aos estudantes já concluintes do ensino médio (UFOPA, 2015). Registra-se que em 2020 ingressou na Ufopa um total de 65 discentes indígenas via PSEl6.

No âmbito da Ufopa, as políticas de ações afirmativas, entendida como compromisso coletivo, estão sob a responsabilidade da Pró-Reitoria de Gestão Estudantil (Proges), setor responsável por desenvolver e coordenar percursos que possam "[...] combater discriminações étnicas, raciais, religiosas, de gênero ou raça, dentro da Universidade [...]" (UFOPA, 2015, p. 59). Entre suas principais atribuições está a de "[...] coordenação, fiscalização e a execução dos auxílios estudantis [...]" (UFOPA, 2015, p. 115), principalmente, aos estudantes indígenas como forma de contribuir com a permanência na universidade. Nesse sentido, destacam-se dois programas desenvolvidos na Ufopa: Auxílio Permanência Especial e Inclusão Digital.

O Programa Auxílio Permanência Especial visa à concessão de um valor que possa contribuir nos custeios de moradia, transporte e material didático-pedagógico aos estudantes ingressantes por processos seletivos especiais, a exemplo, o PSEl, consolidando-se como iniciativa favorável ao desenvolvimento estudantil, mesmo ciente que tais valores ainda são desproporcionais diante dos custos elevados da sociedade (SOARES; COLARES; FERREIRA, 2020). No decorrer dos anos, o programa já ofertou um quantitativo expressivo de bolsas: 58 (2012), 123 (2013), 172 (2014), 272 (2015) e 272 (2016), sendo ofertado gradativamente na instituição (UFOPA, 2015).

Já o Programa Inclusão Digital, também pautado na finalidade de garantir a permanência do estudante na Ufopa, tem como dinâmica a utilização das Tecnologias de Informação e Comunicação "[...] orientadas ao desenvolvimento social, econômico, político, cultural, ambiental e tecnológico, centrados nas pessoas, em especial nos estudantes indígenas

\footnotetext{
${ }^{6}$ Conforme informações disponíveis em:

http://www.ufopa.edu.br/media/file/site/proen/documentos/2020/496f0669c534ae525a295d 04c4c5ea25.pdf.
} 
[...]" (UFOPA, 2015, p. 19), considerando o domínio das tecnologias como requisito básico no ensino superior, especialmente, em tempos de pandemia.

Com a Resolução $N^{\circ}$ 200/2017, que institui a Política de Ações Afirmativas e Promoção da Igualdade Étnico-Racial na Ufopa e estabelece diretrizes para a consolidação do Instituto de Formação Interculutral, compreende-se o termo "ação afirmativa", de acordo com o Art. $3^{\circ}$, como "[...] conjunto de medidas e ações, específicas e especiais, necessárias para contribuir com a afirmação da dignidade, da identidade e da cultura de grupos discriminados e vitimizados pela exclusão social [...]" (UFOPA, 2017b).

Positivamente, a Resolução No 314/2019 vem efetivar a inclusão de negros, quilombolas, indígenas e pessoas com deficiência nos programas de pós-graduação stricto sensu da instituição (UFOPA, 2019b). Tais iniciativas sinalizam "[...] o crescente reconhecimento da importância da educação [...] superior [...]" aos povos indígenas, percurso positivo ao considerar "[...] a posição [...] que o Brasil ocupa nas políticas públicas voltadas à cidadania democrática e à justiça social" (SOARES; COLARES; FERREIRA, 2020, p. 77).

Outra iniciativa favorável mostra-se na aprovação e implementação do Programa de Formação Básica Indígena (FBI), viabilizando o ingresso e permanência de "[...] acadêmicos indígenas, antes de ingressarem regularmente nos cursos escolhidos, com o intuito de minimizar os problemas socioculturais e linguísticos que os impedem de obter melhor aproveitamento acadêmico [...]" (UFOPA, 2017a), corroborando na diminuição dos índices de evasão. O programa tem duração de dois semestres, contemplando as seguintes áreas: Ciências Exatas, Ciências Humanas, Tecnologias e Letras Língua Porguesa, integradas a partir de ações de pesquisa e extensão (UFOPA, 2017a), totalizando 560h de formação básica no âmbito da Ufopa.

$\mathrm{Na}$ sua proposta pedagógica, a $\mathrm{FBI}$ "[...] deverá trabalhar [...] as dimensões étnico-racial, política, pedagógica e epistemológica em busca de efetivar um diálogo interepistêmico e intercultural entre diferentes paradigmas civilizatórios" (UFOPA, 2017a), no intuito de minimizar as dificuldades comuns de adaptação e estranheza com o novo ambiente de 
ensino, de forma que, ao chegar ao curso escolhido no ingresso, sinta-se apto em cumprir as demandas existentes.

Soma-se a este, o Projeto Ceanama7, coordenado pela Pró-Reitoria de Ensino (Proen), cuja finalidade é desenvolver ações de ensino/acompanhamento pedagógico aos estudantes indígenas por meio da concessão de bolsas de monitoria a estudantes ingressantes via processo seletivo regular. Em linhas gerais, estes bolsistas monitores devem auxiliar os estudantes indígenas a inserir-se no ambiente acadêmico, dominando as técnicas necessárias ao bom rendimento educacional. No segundo semestre de 2019 foram concedidas 85 bolsas de monitoria, distribuídas entre as unidades acadêmicas da sede (Santarém) e nos demais Campus Universitários (Alenquer, Itaibuta, Monte Alegre, Juruti, Óbidos e Oriximiná), no valor de $R \$ 400,00^{8}$. Outras iniciativas também oferecem apoio pedagógico aos estudantes indígenas na Ufopa, entre eles, o Projeto Baobá.

Quanto à organização acadêmica, a Ufopa dispõe hoje de inúmeros projetos de extensão, ensino e pesquisa, bem como grupos de estudos, direcionados ao tema da educação indígena e a produção de conhecimentos que visam corroborar na garantia de direitos e sua efetivação na realidade amazônica (SOARES; COLARES; COLARES, 2020). Corroborando com tais iniciativas, a Resolução $N^{\circ} 278$ do Conselho de Ensino, Pesquisa e Extensão (Consepe) da Ufopa, institui o Programa Especial de Ajuste de Percurso Acadêmico, prevendo corrigir desvios e evasões dos estudantes pertencentes a grupos étnicos, como indígenas e quilombolas. $O$ Programa tem início, a partir da Portaria Eletrônica No 33/2019, que nomeia uma comissão específica para: executar e avaliar o programa de ajuste de percurso acadêmico; auxiliar o núcleo docente estruturante e alinhá-lo

\footnotetext{
7 O termo CEANAMA em Nheengatu significa "meu parente, meu amigo". Trata-se de uma ação institucional direcionada ao acompanhamento dos estudantes indígenas, auxiliando na superação de dificuldades enfrentadas: como o domínio da Língua Portuguesa, os conhecimentos matemáticos, a utilização das tecnologias educacionais, entre outras.

8 Informações extraídas do Edital № 031/2019 - PROEN -Monitoria CEANAMA. Disponível em: http://www.ufopa.edu.br/media/file/site/proen/documentos/2019/6f839f183101c37fe88c865 2f67081e4.pdf.
} 
diante das demandas do programa (UFOPA, 2019a), contribuindo na resolução de conflitos formativos em torno da presença indígena na Ufopa.

Atualmente, a instituição atende um total de 482 estudantes indígenas matriculados, sendo sua maior concentração em três cursos específicos: Ciências Biológicas, Bacharelado Interdisciplinar em Ciências e Tecnologia das Águas e Pedagogia, com consideráveis índices de presença nos demais, conforme o Quadro de $N^{\circ} 1$ e $N^{\circ} 2$.

QUADRO 1 - Estudantes indígenas nos cursos Licenciaturas da Ufopa.

\begin{tabular}{|l|c|}
\hline \multicolumn{2}{|c|}{ ESTUDANTES INDIÍGENAS POR CURSOS DE LICENCIATURAS } \\
\hline \multicolumn{2}{|c|}{ PRESENÇA INDÍGENA } \\
\hline Ciências Biológicas & 38 \\
\hline Licenciatura Integrada em Matemática e Física & 18 \\
\hline Pedagogia & 33 \\
\hline Letras - Português e Inglês & 27 \\
\hline Informática Educacional & 16 \\
\hline História & 15 \\
\hline Licenciatura Integrada em Biologia e Química & 9 \\
\hline Geografia & 7 \\
\hline Licenciatura Integrada em História e Geografia & 6 \\
\hline Química TOTAL DE ESTUDANTES INDÍGENAS & 3 \\
\hline \multicolumn{2}{|c|}{ TOT2 } \\
\hline
\end{tabular}

Fonte: elaborado pelos autores com base em relatórios do SIGAA, 2021.

QUADRO 2 - Estudantes indígenas nos cursos de Bacharelados e Interdisciplinares da Ufopa.

\begin{tabular}{|l|c|}
\multicolumn{2}{|c|}{ CSTUDANTES INDÍGENAS POR CURSOS DE BACHARELADOS E INTERDISCIPLINARES } \\
\hline \multicolumn{1}{|c|}{ PRESENÇA INDÍGENA } \\
\hline Farmácia & 14 \\
\hline Gestão Pública e Desenvolvimento Regional & 14 \\
\hline Ciências da Computação & 13 \\
\hline Ciências Econômicas & 13 \\
\hline Engenharia de Pesca & 12 \\
\hline Zootecnia & 10 \\
\hline Sistemas de Informação & 16 \\
\hline Direito & 17 \\
\hline Arqueologia & 16 \\
\hline Engenharia Florestal & 16 \\
\hline Antropologia & 19 \\
\hline Agronomia & 21 \\
\hline Interdisciplinar em Ciências e Tecnologia das Águas & 33 \\
\hline Interdisciplinar em Saúde & 20 \\
\hline Interdisciplinar em Ciências Agrárias & 16 \\
\hline Interdisciplinar em Ciência e Tecnologia & 15 \\
\hline \multicolumn{2}{|c|}{ TOTAL DE ESTUDANTES INDÍGENAS } \\
\hline
\end{tabular}

Fonte: elaborado pelos autores com base em relatórios do SIGAA, 2021.

Além desses, em número menor que 10, existem indígenas distribuídos nos seguintes cursos: Administração (1); Geologia (4); Engenharia de Minas 
(4); Ciências Atmosférias (5); Geofísica (6); Engenharia Civil (8); Biotecnologia (9); Interdisciplinar em Ciências da Terra (5); e outros em cursos não identificados (3), somando 45 estudantes.

Na região amazônica, especialmente, na Área de Atuação Direta (AAD) da Ufopa, foram identificados "[...] 28 povos, os quais, de acordo com a [...] FUNAl, vivem em 21 [...] Terras Indígenas [...], cuja demarcação compreende $145.644 \mathrm{~km}^{2}$. Dentre essas [...], 16 correspondem a $42 \%$ da área total da AAD Ufopa" (UFOPA, 2017a). Nesse sentido, dos 482 estudantes indígenas matriculados, a maior parte destes encontra-se nas etnias Wai Wai e Munduruku, pressupondo que essa população seja predominante na região, mesmo sob a identificação de outras: Manhuary, Chipaia, Kaxuyana, Korap, Megrangnotire, Passaranuk, Puchu, Txenama, Waryanka, etc. Assim, o tópico seguinte trata da percepção docente em torno desta presença, identificando práticas, desafios e perspectivas no âmbito da Ufopa.

\section{O INDÍGENA NO ENSINO SUPERIOR: e agora professor?}

A presença indígena nas salas de aula universitária da Ufopa, como visto acima, não é mais uma questão isolada desse ou aquele curso, agora assume interesse de todas as áreas do conhecimento, remetendo a uma questão: e agora professor? As percepções docentes estão contempladas nas falas de 35 professores, de cursos e institutos diversos da Ufopa, conforme informações sistematizadas no Quadro de $N^{\circ} 3$ e Nº 4 .

QUADRO 3 - Distribuição/atuação dos docentes nos Campi da Ufopa fora da sede.

\begin{tabular}{|c|c|c|}
\hline $\begin{array}{c}\text { Instituto/Unidade } \\
\text { Acadêmica }\end{array}$ & Cursos ofertados na Graduação & $\mathrm{N}^{\circ}$ de Docentes \\
\hline $\begin{array}{l}\text { Campus } \\
\text { Oriximiná }\end{array}$ & Ciências Biológicas e Sistema de Informação. & 04 \\
\hline Campus Itaituba & Engenharia Civil. & 01 \\
\hline $\begin{array}{l}\text { Campus } \\
\text { Alenquer }\end{array}$ & Administração. & 01 \\
\hline Campus Itaituba & Engenharia Civil. & 01 \\
\hline Campus Óbidos & Pedagogia. & 01 \\
\hline \multicolumn{2}{|r|}{ TOTAL: } & 08 \\
\hline
\end{tabular}

Fonte: elaborado pelos autores com base nas respostas dos questionários aplicados, 2021. 
QUADRO 4 - Distribuição/atuação dos docentes nos Institutos Acadêmicos da Ufopa.

\begin{tabular}{|l|c|}
\hline \multicolumn{2}{|c|}{ DISTRIBUIÇÃO DE DOCENTES NOS INSTITUTOS/UNIDADES ACADÊMICAS DA UFOPA } \\
\hline \multicolumn{1}{|c|}{ Instituto/Unidade Acadêmica } & N $^{\circ}$ de Docentes \\
\hline Instituto de Ciências da Educação (ICED) & 07 \\
\hline Instituto de Biodiversidade e Florestas (IBEF) & 07 \\
\hline Instituto de Engenharia e Geociências (IEG) & 02 \\
\hline Instituto de Ciências da Sociedade (ICS) & 04 \\
\hline Instituto de Ciências e Tecnologias das Águas (ICTA) & 03 \\
\hline Instituto de Saúde Coletiva (ISCO) & 03 \\
\hline Centro de Formação Interdisciplinar (CFI) & 01 \\
\hline
\end{tabular}

Fonte: elaborado pelos autores com base nas respostas dos questionários aplicados, 2021.

Em análise aos Quadros de $N^{0} 3$ e 4, fica evidente que a maior concentração dos docentes participantes do estudo encontra-se no ICED e no IBEF. Assim, do conjunto de disciplinas de cada curso, todos requerem habilidades e competências diferenciadas por parte dos estudantes, considerando o caráter técnico-aplicado em determinados componentes curriculares. Portanto, são amplos os percursos formativos dos cursos da Ufopa, necessitando de competência técnica para um acompanhamento exitoso. Reforça-se, nesse caso, o investimento em ações que estimulem tais aquisições aos discentes indígenas (SOARES; COLARES; FERREIRA, 2020).

No aspecto da formação/titulação dos docentes, contabilizou-se 19 (54\%) doutores, 15 (43\%) mestres e apenas 01 (3\%) especialista Lato Sensu, pressupondo a existência de competência técnica suficiente para organizar a dinâmica educativa. Todavia, é necessário sublinhar as especificidades dessa formação, como as ciências exatas, cujo currículo não aborda temáticas da diversidade, discussões comuns nas ciências humanas (CINEP, 2010).

Nesse sentido, ao tratar do planejamento das atividades em turmas com estudantes indígenas, os docentes foram questionados quanto ao formato e/ou adaptação dos conteúdos ministrados diante das dificuldades que o público em questão vem apresentando ao longo dos anos, principalmente, na apropriação da Língua Portuguesa, enquanto norma padrão. Ao lançar a seguinte questão, "Enquanto docente de estudantes indígenas, como você planeja suas atividades para esse público?", o Gráfico de $N^{\circ} 1$ apresenta alguns resultados. 
Gráfico 1 - Representação sobre o planejamento e organização da ação educativa.

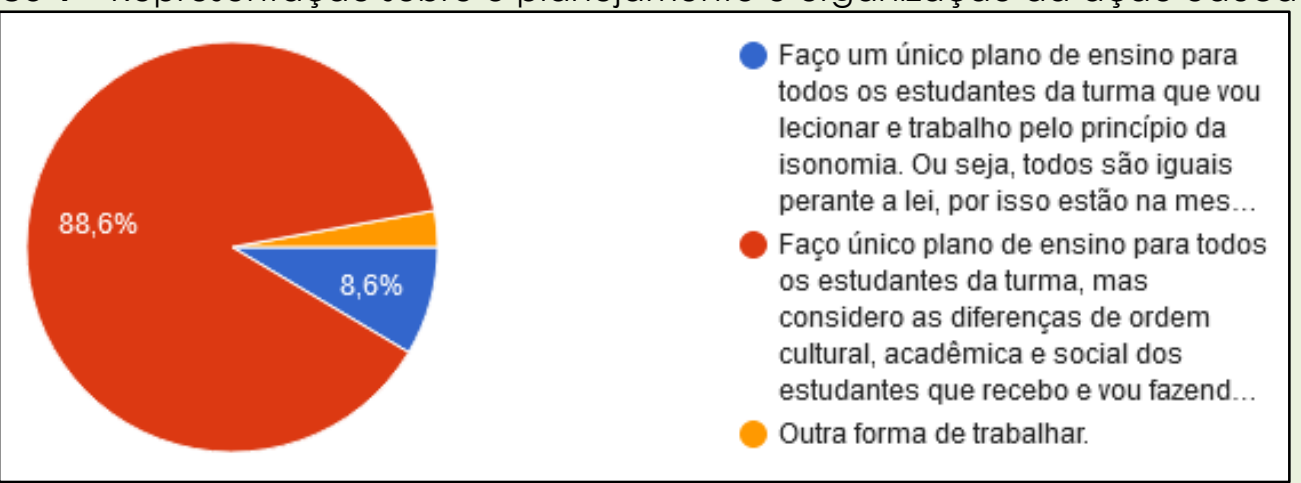

Fonte: elaborado pelos autores com base nas informações dos questionários, 2021.

É predominante, no conjunto das respostas, a confirmação de que um único plano é feito no decorrer das disciplinas, gerando duas questões: a primeira positiva, no sentido de firmar o princípio da igualdade, sem haver distinções a partir da condição histórico-social de cada estudante; já a segunda é negativa por não viabilizar a aplicação de atividades diferenciadas a estes estudantes o que, de certa forma, poderá reforçar as condições de discriminação na sala de aula. Todavia, o fato é o que o docente não tem muitas opções, já que estes, em sua maioria, pouco contato e/ou formação tiveram para trabalhar com esse público em questão (CINEP, 2010). Daí justifica-se a contrariedade que se impõe entre as prescrições legais e a materialidade dos direitos nos espaços públicos (SOARES; COLARES; COLARES, 2020), principalmente, nas universidades enquanto lócus de formação social. Além disso, 2,8\% dos docentes informaram que utilizam outras formas de trabalho com os alunos indígenas, pela adoção da prática da avaliação diferenciada, acrecida da opção de uma avaliação extra, no caso da reprovação, voltando-se aos conhecimentos de sua realidade. Fato contestado pelos que defendem a isonomia acadêmica, no sentido de privilegiar tais sujeitos, ao mesmo tempo em que os substimam quanto suas capacidades intelectuas (CINEP, 2010).

Sobre as dificuldades cotidianas na sala de aula, referente aos aprendizados dos conteúdos curriculares, classificam-se os problemas existentes, a partir dos relatos obtidos dos docentes, em três grandes eixos: 1. De ordem comunicacional ou linguística; 2 . De ordem intectual e acadêmica; 3 . De ordem social. 
No campo das dificuldades de ordem comunicacional ou linguística, sobressai a não compreensão da Língua Portuguesa, não permitindo um acompanhamento proveitoso das atividades ministradas, já que a maior parte dos professores desconhece e, mesmo que soubessem, não poderiam ministrar aulas na língua indígena, pois, entre o seu público estão outros sujeitos, com maior predominância, os falantes da língua padrão. Aí reside uma importante questão para se pensar em possibilidades que superem tal conflito (CINEP, 2020), pois, de acordo com o relato de um docente entrevistado, compreende-se que:

Os alunos indígenas precisam de cursos e acompanhamento contínuo quanto ao aprendizado do português, é muito difícil para um professor de disciplinas com viés mais técnico fazer esse acompanhamento. Eu, particularmente, tento aproximar os conteúdos da realidade dos indígenas, pois algumas disciplinas são fáceis para isso, como as ecologias, limnologia, ecologia humana, mas quando entra alguns conceitos ou a parte matemática dos conteúdos torna-se bem difícil um acompanhamento mais próximo, pois toda a turma possui dificuldades básicas (Docente 29, 2020).

Além disso, limitada a comunicação destes sujeitos por não dominar a língua padrão, muitos docentes relatam dificuldades em compreender a escrita dos estudantes, sem contar com o fato de que, quase sempre, os exercícios e atividades entregues não correspondem ao que foi solicitado, devendo encontrar meios adequados de aproveitar aquele material e lançar a nota. Corrobora-se a este, uma visível ausência de comunicação entre as coordenações de cursos, os sistemas de armanezamento de dados da instituição e os docentes, pois, deveriam ser especificados na lista quais são os estudantes indígenas da referida turma, o que, segundo um dos entrevistados, não ocorre, enfraquecendo suas chances de intervenção.

Observo um grande problema de comunicação. Quando recebemos a listagem de alunos (sigaa) não temos a informação de quais são os indígenas ou quilombolas. Nem sempre o sobrenome o caracteriza. Então não temos como reconhecê-lo e prestar alguma assistência diferenciada. Várias vezes aconteceram de só ficar sabendo no final do semestre, quando não havia mais tempo hábil. Minha opinião é que é muito difícil a Universidade suprir as deficiências de aprendizagem do ensino fundamental e médio desses alunos (Docente 23, 2020). 
Dos problemas de ordem intectual e acadêmica, evidenciam-se aspectos negativos com relação às práticas educativas em sala de aula, muitas vezes relacionadas a um "baixo rendimento devido à formação precária na Educação Básica" (Docente 28, 2020), chegando ao ensino superior com posturas e formações incompatíveis, o que dificulta ainda mais o processo. Entre estes, a falta de interesse dos estudantes, seja por não enxergar este ensino como significativo e alinhado aos seus anseios ou ainda por não compreender sua execução, secundariza o compromisso firmado no ato do processo seletivo de ingresso na Ufopa. Nesse contexto, identificase ainda a prática do não cumprimento das avaliações e entrega de atividades em tempo acordado, restando ao docente estar insistindo, em alguns casos, para o recebimento ou, em outros, reprovando-os. Sobre esta questão, apresenta-se o seguinte relato:

[...] vejo que ao ingressarem na universidade, além de receberem as aulas de português e outras triviais para a sua vivência [...], eles precisam receber aulas de cidadania, para que fique explícito a eles as regras as quais serão submetidos e que devem ser respeitadas. Já tive casos, por exemplo, de alunos que simplesmente sumiram das aulas sem dar nenhuma satisfação e ao final do semestre apareceram e não alegaram estar doentes ou qualquer outro problema grave, simplesmente sumiram. Quando perguntei o motivo, eles só balançaram os ombros e não tinham o que falar, como se a sua ausência não fosse importante (Docente 15, 2020).

Questões desta natureza projetam um grande desafio ao trabalho docente, pois, práticas conflituosas só reforçam a inferioridade deste público nos espaços universitários, o que não deveria ocorrer. Também é válido ressaltar os precários conhecimentos sobre os instrumentos tecnológicos, como computadores e sistemas digitais, dificultando a realização das atividades que acontecem em interação com o ambiente virtual do Sistema Integrado de Gestão de Atividades Acadêmicas (Sigaa).

Em relação às dificuldades de ordem social, ocasionadas em detrimento da condição histórica destes sujeitos, os docentes indicam que ocorrem inúmeras situações de discriminação com os estudantes indígenas em sala de aula, exigindo sua capacidade de intervir na mediação e resolução dos conflitos. Como já foi dito anteriormente, talvez essa grande 
"flexibilização e diferenciação de atividades e avaliações" possa estar corroborando nessa situação. Porém, vale lembrar que o docente permanece sempre em duas saídas: ou mantém o nível de exigências em igualdade, resultando em índices desfavoráveis (por conta da precária formação do estudante indígena) ou realiza ações diferenciadas, causando situações de discriminação e inferioridade na sala de aula. Eis outro grande desafio nos espaços universitários, pois, vislumbra-se que:

Uma dificuldade que observo é o preconceito por parte dos discentes não indígenas, com exceção dos de origem quilombola. Os alunos indígenas tem grande dificuldade em entrar nos grupos para trabalho em equipe. Por vezes, eu tenho que interferir (Docente $3,2020)$.

Há ainda a preocupação em torno de uma dessintonia com as regras sociais, principalmente, no cumprimento de prazos e acordos coletivos, gerando preocupação no trabalho docente quanto à efetivação do conhecimento necessário para aprovação no componente curricular, considerando as ausências nas aulas, a não entrega de atividades e o não cumprimento e respeito por decisões tomadas em conjunto. Nessa questão, paira sempre o velho dilema: "se reprová-los, eles perdem a bolsa" (Docente 29, 2020), restando ao docente à decisão, de certa forma, sobre o futuro destes na universidade. Assim, ressalta-se o seguinte posicionamento:

Percebo que os discentes indígenas apresentam dificuldades de
compreensão de vivências em sociedade. Como exemplo, a
importância de prazos, as obrigações que eles têm de frequentar as
aulas, de entregar trabalhos avaliativos, de procurar auxílio dos
monitores e do próprio professor (Docente 5,2020 ).

Ao serem questionados sobre a existência das políticas de ações afirmativas da Ufopa, bem como sua implementação no processo ensinoaprendizagem, verificou-se que: 15 (43\%) dos docentes as conhecem, 12 (34\%) conhecem superficialmente e 08 (23\%) desconhecem totalmente estas políticas e ações. Portanto, é considerável que 20 docentes não apresentam total domínio sobre os percursos necessários para a efetivação do conjunto de resoluções e programas da Ufopa, o que, por si só, é autoexplicativo quanto às incoerências entre a organização e a avaliação das disciplinas 
para estes estudantes. Outra questão é que não se procura buscar tais normativas como eixos norteadores da construção dos planos de ensino, tentando efetivar procedimentos que não consideram a existência das diversidades na sala de aula. Isso, sem dúvidas, é preocupante (CINEP, 2010).

Ao investigar, com os docentes que afirmam conhecer tais políticas de ações afirmativas, quais têm sido as atividades desenvolvidas pela Proges/Ufopa na cotidianidade universitária, a maioria cita o Projeto de Monitoria Ceanama e a concessão de auxílios financeiros, mas nada de concreto que indique mudanças nas práticas educativas, como da oferta de formação docente para o trabalho com estudantes indígenas e de intervenções sociais formativas para validar o compromisso assumido por estes estudantes junto à universidade (SOARES; COLARES; FERREIRA, 2020).

Por fim, quanto às perspectivas de melhorias do processo ensinoaprendizagem, os docentes recomendam: a criação de materiais didáticopedagógicos de temas relacionados ao curso escolhido e sua transposição também na língua indígena como forma de conceder significado as aprendizagens em sala de aula; a realização e continuidade de cursos de formação específicos para a língua indígena9 aos docentes; inserir as peculiaridades indígenas (saberes, culturas, tradições) no currículo de formação dos cursos de nível superior; e implementar grupos coletivos de estudo e discussão das políticas de ações afirmativas da universidade a fim de encontrar caminhos para tais efetividades; e efetivar os cursos de língua portuguesa como obrigatórios ao longo da formação, assim como a língua indígena. Como afirma um dos docentes:

[...] creio que podemos criar mais [...] ações que valorizem a identidade de cada etnia e traga maior autoestima aos indigenas. Uma forma pode ser a criação de espaços multiculturais e atividades de práticas vivenciais com a cultura amazônica (Docente 18, 2020).

Portanto, são inúmeros os desafios postos nas práticas educativas do professor de ensino superior de estudantes indígenas na Ufopa, seja pela ausência de elementos formativos e a ineficiência das políticas públicas

\footnotetext{
${ }^{9}$ A exemplo do curso de Língua Indígena Nheengatu realizado na Ufopa em 2016.
} 
como também pela adoção de instrumentos que distanciam a educação de sua função emancipatória. O fato é que, ano após anos, o número de estudantes indígenas só faz aumentar, sendo os docentes instados a se posicionarem, a reverem sua atuação profissional, pois, a partir do momento que a instituição implementa sua política de ações afirmativas, esta torna-se um compromisso de todos. E agora professor? E agora gestores?

\section{CONSIDERAÇÕES FINAIS}

Do conjunto de discussões, os resultados mostram inúmeros desafios postos no trabalho docente com estudantes indígenas. Em síntese, verificouse que a Ufopa instituiu sua política de ações afirmativas e de promoção da igualdade étnico-racial, embora nem todos os docentes a conheçam plenamente, enfraquecendo a materialidade dos processos; que não há consenso quanto ao planejamento das práticas docentes para às aulas, considerando o público diverso e multicultural; que alguns reconhecem a necessidade de maior investimento institucional em relação à formação docente para atuar com esse público diverso.

Assim, visando superar os dilemas nas práticas curriculares, os docentes apontam: a criação de materiais específicos na língua indígena; oferta obrigatória de cursos de língua portuguesa; e a inserção de questões indígenas no currículo, como possibilidades de redução dos atuais conflitos.

É perceptível ainda que, apesar do quantitativo de estudantes indígenas na Ufopa e da existência de Políticas de Ações Afirmativas, a assistência pedagógica não tem sido plenamente garantida na formação destes estudantes, ensejando mais investimento na formação continuada dos docentes que, sem a preparação adequada para isso, reproduzem as práticas do currículo oficial. Os indígenas estão ocupando seus lugares de direito e aqui buscam a validação dos seus saberes, da sua cultura e das suas necessidades locais. É necessário, portanto, interculturalizar o currículo oficial e saber lidar com os conflitos e demais ocorrências no ambiente universitário, que demande um diálogo intercultural. 
Em linhas gerais, dispõe-se de um acervo bem estruturado de políticas, mas poucas têm realmente se materializado na instituição. Sinaliza-se a necessidade da revisão, avaliação e engajamento de grupos coletivos por mudanças estruturais. E uma das principais categorias que precisa cobrar essas melhorias formativas são os docentes, pois, estão postos ao desafio de formar estudantes em alinhamento com suas expectativas e de seus povos. Portanto, uma longa caminhada está posta. É preciso avançar!

\section{REFERÊNCIAS}

BANIWA G. A Lei das cotas e os povos indígenas: mais um desafio para a diversidade. Cadernos do Pensamento Crítico Latino-Americano. LACED, 2013.

BRASIL. Lei ${ }^{\circ}$ 9.394, de 20 de dezembro de 1996. Brasília: Presidência da República, 1996. Disponível em: http://www.planalto.gov.br/ccivil_03/leis/19394.htm Acesso: 15 jan. 2021.

BRASIL. Lei $\mathbf{n}^{\circ} \mathbf{1 2 . 7 1 1}$, de 29 de agosto de 2012: dispõe sobre o ingresso nas universidades federais. Brasília: Presidência da República, 2012. Disponível em http://portal.mec.gov.br/cotas/docs/lei_12711_29_08_2012.pdf Acesso: 12 jan. 2021.

BRASIL/MEC. Portaria № 438, de 28 de maio de 1998: Institui o Exame Nacional do Ensino Médio, como procedimento de avaliação do desempenho do aluno. Disponível em: http://www.editoramagister.com/doc_Acesso: 22 jan. 2021.

CINEP. Esboço de um perfil do estudante indígena no ensino superior. In: LUCIANO, G. J. dos S.; OLIVEIRA, J. C. de; HOFFMANN, M. B. (Orgs.). Olhares indígenas contemporâneos. Brasília: CIEP, 2010, p. 204-260.

COLLET, C.; PALADINO, M.; RUSSO, K. Quebrando preconceitos: subsídios para o ensino das culturas e histórias dos povos indígenas. Rio de Janeiro: Contra Capa Livraria; Laced, 2014.

CUNHA, L. A. Ensino Superior e Universidade no Brasil In: LOPES, E. M. T.; FARIA FILHO, L. M.; VEIGA, C. G. (Orgs.). 500 anos de Educação no Brasil. $5^{a}$ ed. Belo Horizonte: Autêntica, 2015.

MEJÍA JIMÉNEZ, M. R. Diálogo-confrontación de saberes y negociación cultural: ejes de las pedagogías de la educación popular:una construcción desde el sur. Educar em Revista, Curitiba, n. 61, jul./set. 2016, p. 37-53. Disponível em:

https://www.scielo.br/pdf/er/n61/1984-0411-er-61-00037.pdf Acesso: 18 fev. 2021.

RODRIGUES, G. C. L. Quando a escola é uma flecha: educação escolar indígena e territorialização na Amazônia. Revista Exitus, Santarém/PA, v. 8, n. 3, set./dez., 2018, p. 396-422. Disponível em:

http://www.ufopa.edu.br/portaldeperiodicos/index.php/revistaexitus/article/view/65 Acesso: 20 fev. 2021. 
SOARES, L. de V.; COLARES, M. L. I. S.; COLARES, A. A. A efetivação do direito à educação pública na Amazônia: dilemas diante de suas singularidades. Revista Humanidades e Inovação, v. 7, n. 15, 2020, p. 167-183. Disponível em: https://revista.unitins.br/index.php/humanidadeseinovacao/article/view/2835 Acesso: 18 jan. 2021.

SOARES, L. de V.; COLARES, M. L. I. S.; FERREIRA, M. A. V. Políticas educacionais na Amazônia: a questão "indígena" no ensino superior. Revista Teias, v. 21, n. 61, abr./jun., 2020, p. 68-80. Disponível em: https://www.epublicacoes.verj.br/index.php/revistateias/article/view/49558 Acesso: 20 jan. 2021.

UFOPA. Aditamento do Plano de Desenvolvimento Institucional (PDI) da Ufopa. Santarém, PA: Dirigentes da Administração Geral, 2015. Disponível em: http://www.ufopa.edu.br/pdi/public/uploads/arquivos/pdi_20122016_aditamento.pdf Acesso: 22 jan. 2021.

UFOPA. Portaria Eletrônica N³3/2019. Santarém: Reitoria, 2019a. Disponível: http://www.ufopa.edu.br/media/file/site/proges/documentos/2020/904997f300f94d9 aea742d655be0451b.pdf Acesso: 30 jan. 2021.

UFOPA. Resolução № 194 de 24 de abril de 2017: Projeto de Formação Básica Indígena da Ufopa. Santarém: CONSEPE, 2017a. Disponível em https://sigaa.ufopa.edu.br/sigaa/verProducao?idProducao=205800\&key $=456 \mathrm{cc} 24 \mathrm{bf}$ Ob7e5074f76947ce125040f Acesso: 20 jan. 2021.

UFOPA. Resolução N² 200 de 08 de junho de 2017. Santarém: CONSEPE, 2017b. Disponível em:

http://www.ufopa.edu.br/media/file/site/proges/documentos/2018/ef501080a526bd ffadb4c6d31c42a809.pdf Acesso: 27 jan. 2021.

UFOPA. Resolução N³14 de 23 de dezembro de 2019. Santarém: CONSEPE, 2019b. Disponível em:

http://www.ufopa.edu.br/media/file/site/proges/documentos/2020/57d9ea5577edf 0b8cfb9a557d4f7b385.pdf Acesso: 28 jan. 2021.

VIANA, F. de L. B. et al. Indígenas no ensino superior: as experiências do programa Rede de Saberes, em Mato Grosso do Sul. $1^{a}$ ed. Rio de Janeiro: E-Papers, 2014. Disponível em: http://www.laced.etc.br/livros Acesso: 12 jan. 2021.

Recebido em: 06 de fevereiro de 2021. Aprovado em: 09 de junho de 2021. Publicado em: 11 de junho de 2021. 